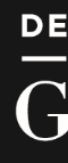

\title{
MANAGING ACADEMIC INTERNATIONALIZATION: A CULTURE-BASED APPROACH
}

\author{
Eva-Nicoleta, BURDUȘEL ${ }^{1}$ and Camelia, OPREAN ${ }^{2}$ \\ 16"Lucian Blaga” University of Sibiu, Sibiu, Romania, eva.burdusel@ulbsibiu.ro \\ 2“Lucian Blaga” University of Sibiu, Sibiu, Romania, camellia.oprean@ulbsibiu.ro
}

\begin{abstract}
The goal of the present paper is apply the blue-ocean strategy to the current status of the higher education system, with a major focus on managing cultural diversity in a global world. Universities nowadays represent poles of excellence in terms of cultural innovation, knowledge creation and transfer to the industry, an interface between home and host country as regards academic mobility (teaching and research mobility); they have a significant role in promoting cultural values and informed intercultural communication, creating academic consortia as well as interacting with the local and business communities. The paper shall also redefine: the role of university managers in the context of expanding internationalization, both in terms of student / staff mobility and developing research networks; the relation of universities and higher education to the needs of society, in view of attaining economic growth and technological advancement. In this respect, the cultural centres affiliated to HEIs represent the best vehicle for raising cultural awareness, informed and coherent understanding of „otherness”, overcoming the „either/or” perspective. University differentiation and diversity are key components of current European strategies as illustrated by several documents: New Skills for New Jobs: Action Now; Europe 2020: A Strategy for Smart, Sustainable and Inclusive Growth; EDU 2025; Blue Ocean Strategy; The FOR-UNI Blueprint; 2005 UNESCO Convention on Cultural Diversity. Managing cultural diversity in a global world has become equally a challenge and a prerequisite for higher education institutions in view of their survival on a highly competitive market and will eventually render sustainable advantage at national and international level. Cultural centers affiliated with universities represent poles of excellence in terms of facilitating and promoting interculturality, plurilingualism, staff and student mobility as well as an exchange of teaching and research practices. In this context, the Confucius Institute at "Lucian Blaga" University of Sibiu represents an example of best practice in terms of efficient management and anticipatory leadership.
\end{abstract}

KEYWORDS: University governance, academic internationalization, management, leadership

MOTTO: "Cultural diversity is a defining characteristic of humanity ... emphasizing the need to incorporate culture as a strategic element in national and international development policies." (UNESCO Convention on the Protection and Promotion of the Diversity of Cultural Expression 2005)

\section{HIGHER EDUCATION BETWEEN COMPETITION AND COOPERATION}

The goal of the present paper is to provide an interdisciplinary and integrative approach to the current status of the higher education system, with a major focus on managing cultural diversity in a global world. Universities nowadays need to target their strategies, design a vision, state the fundamental mission, capitalize their human and material resources in view of identifying an effective means of positioning in society and thus achieving a balance between two opposites: elitism and consumerism; humanistic and pragmatic perspectives.

Today universities aim to enable students to develop their capacities to the full; in the process, they acquire the intellectual flexibility necessary to meet the demands of a rapidly changing economy. But a university should not provide vocational training in the narrow sense of uncritical indoctrination in the rules and techniques of a particular trade. Institutions which do that are an indispensable part of the higher education system ... Advanced study and research are essential attributes of a university and some of at research will have vital social and industrial applications. But that is not its primary purpose, which is to enhance our knowledge and understanding whether of the physical world or of human nature and all forms of human activity in the present and the past. (Thomas Keith, "Universities under Attack" London Review of Books, Vol 33, no 24, 15 Dec 2011, pp. 9-10. Web 24 March 2014 http://www.lrb.co.uk/v33/n24/keith-thomas/universities-under$\underline{\text { attack })}$

Higher education institutions need to include in their organizational strategy recent concepts such the blue ocean metaphor, lateral thinking in order to attain sustainable competitive advantage. In practice, the blue ocean strategy, as set forth by W. Chan Kim and Renee Mauborgne (Kim, W. Chan and Mauborgne, Renee, Blue Ocean Strategy. How to Create Uncontested Market Space and Make Competition Irrelevant, Harvard Business Review Press, 2005), recommends tapping previously unexplored market space, creation and retaining of new demand with a focus of making the competition irrelevant, instead of pooling all efforts and concentrating resources on beating competitors - a characteristic of organizations in red oceans. Therefore, an initial hypothesis of the present is to advocate the importance of cooperation and that of winning partners rather than fighting competitors since both academic 
and business organizations operate in a highly interdependent context subject to radical and unexpected changes, requiring the ability of lateral thinking which replaces vertical thinking. As Edward de Bono argued "those organizations that focused on competition did badly, those that focused on value creation did well." (De Bono, Edward, New Thinking for the New Millennium, London: Penguin Books, 2000, p. 95). Universities should be more concerned about designing the future rather than analyzing the past. "Universities found it useful to look backwards and ... scholarship attained a high value; unfortunately, they have never recovered from that. Design is a matter of putting together what we know in order to achieve what we want; ... design is the opposite of analysis and judgment; design may be seen as having an "added value". (idem, New Thinking for the New Millennium, London: Penguin Books, pp. 55, 57, 58 (2000)).

Both Martha Nussbaum and Keith Thomas acknowledge the current worldwide crisis in education entailed by ,the pressure for economic growth [which] has led many European political leaders to recast the whole of the university education - both teaching and research - along growth-oriented lines, asking about the contribution of each discipline and each researcher to the economy." (Martha Nussbaum, (2010),, Skills for Life”, TLS,

April 30, p. 15) Hence they call our attention to the relation between universities and their societies subject to a paradigm shift, defined by profitability and pragmatism in terms of academic output, resources efficiency and measurable impact in relation to economic success and technological advancement. „All publicly funded research at universities should have an identifiable ,impact' on our economy and society." (Thomas, Keith, , What are universities for?”, TLS May 7/2010; p.13). To conclude this introductory part, let us not forget that ,for centuries, universities have existed to transmit and reinterpret the cultural and intellectual inheritance, and to provide a space where speculative thought can be freely pursued without regard to its financial value. In a free and democratic society it is essential that that space is preserved." (Thomas, Keith, "Universities under Attack" London Review of Books, Vol 33, no 24, 15 Dec 2011, pp. 9-10. Web 24 March 2014 http://www.lrb.co.uk/v33/n24/keith-thomas/universities-underattack). This statement reinforces the idea expressed length by Martha Nussbaum in defense of liberal education, currently in a state of vulnerability at a time when education for profit seems to prevails as a result of recent policy-making and financial cuts in the academia. (Nussbaum, Martha, Not for Profit. Why Democracy Needs the Humanities, Princeton University Press 2012)

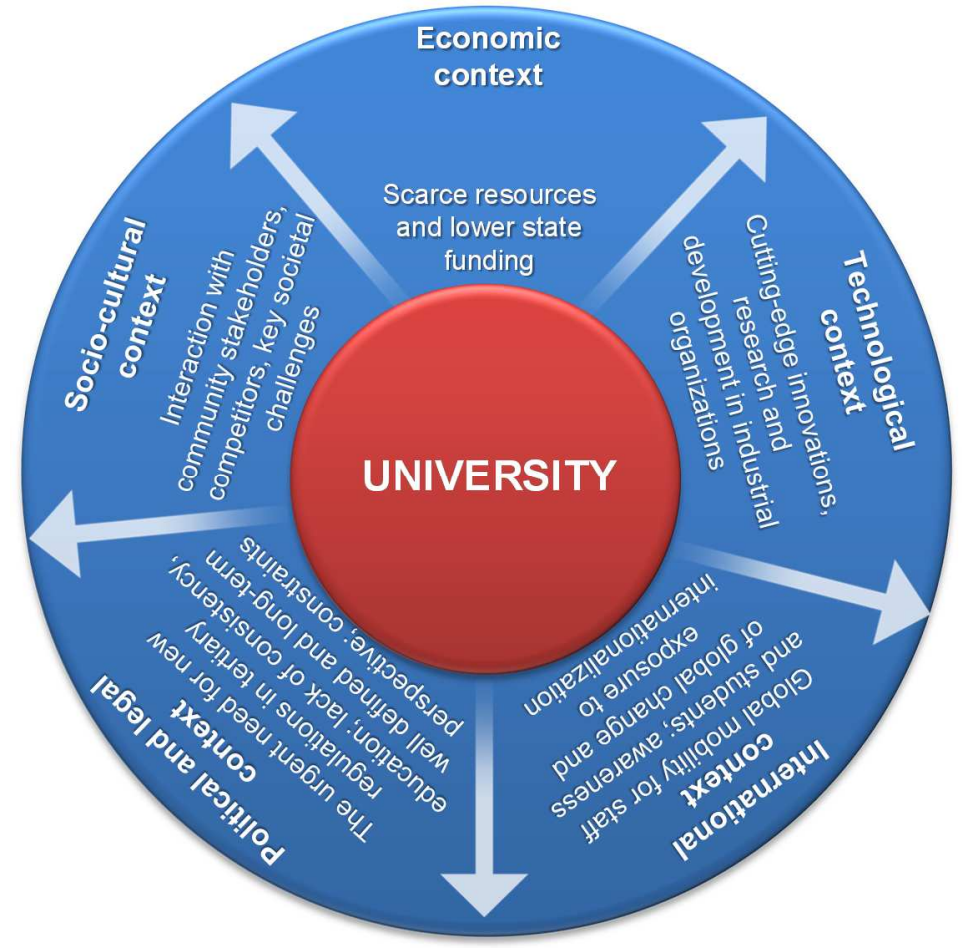

Figure 1. University and its context (Burdusel, E. N.; Oprean, C., "A Holistic Approach to Higher Education: Challenges and Changes for the Sustainable University” in Management of Sustainable Development Journal, vol.3, no.1/2011; pp.31-33)

\section{A PARADIGM SHIFT IN UNIVERSITY GOVERNANCE}

The paper also aims to redefine the role of university managers in the context of expanding internationalization - both in terms of student and staff mobility as well as developing research networks; furthermore, it will examine the relation of universities to the needs of society, in view of attaining economic growth and technological advancement, as they are competing for resources - human, material and financial; and addressability - i.e. national and international visibility, recognition and student recruitment. Given the recent challenges in educational paradigms - a shift from elite to mass education, academic management should evince a change of perspective from a quantitative emphasis (providing short-term institutional profit) to a qualitative approach (for sustainabe development).

There are four imperatives that ,reflect the complex environment in which educational institutions operate. They are the drivers and motivating forces that challenge any institutions to take a proactive stance on quality":

- the moral imperative

- the professional imperative

- the competitive imperative

- $\quad$ the accountability imperative (Sallis, Edward, Total Quality Management in Education, 3rd edition, London: 2002, pp.4-5) 
According to the recent 2020 Development Strategy outlined by LBUS in view of attaining sustainability and excellence in community outreach and increased international visibility, the mission of LBUS is to act as a broker of knowledge and trainer of competencies, underscored by several major principles: coherence and connection of teaching and research processes; international cooperation; quality assurance; university governance and financial management. Furthermore, some of the values lying at the core of institutional development are: entrepreneurship, excellence in research and innovation. (2020 LBUS Development Strategy, pp. 8-10)

As Androulla Vasilliou, European Commissioner for Education, Culture, Multilingualism and Youth, highlighted on the occasion of launching Erasmus+ "education and, in particular higher education, has a growing international dimension"; moreover "education is one of the most powerful tools for shaping our society`s future." (Androulla Vasilliou, European Commissioner for Education, Culture, Multilingualism and Youth, speeches: 13 Sept 2013; 11 March 2014)

New challenges require different approaches to academic management, changes in management style, firmly rooted in the conviction that a high performing organization depends on effective leadership and self-development; "leaders must have the vision and be able to translate it into clear policies and specific goals." (Sallis, Edward, Total Quality Management in Education, 3rd edition, London: 2002, p. 75). According to John Adair, effective leadership will be reflected by a set of guidelines that help define and shape the high performance team: i.e. "clear realistic objectives; shared sense of purpose; best use of resources; atmosphere of openness; reviews progress; builds on experience; rides out storms." (Adair, John, Not Bosses but Leaders, London: Kogan Page Limited, 1991, p.73). The roles of managers and leaders might overlap significantly, however they are not identical; whereas managers focus on the present performance and available resources, are skilled at analysis, organizing, controlling and assessing and deal with tangible assets; leaders have the ability to think ahead, design strategies and evince a high degree of innovative and creative vision; they focus on growth and deal with human capital. "The practice of leadership is an art; the practice of management is a science ... managers are necessary, leaders are essential." (Idem, p.61)

In this context, higher education institutions have become increasingly aware of the relevance of academic internationalization, evinced by the fact that the top management of Romanian HEIs includes a vice-rector for international relations. Internationalization represents an important dimension for Lucian Blaga University of Sibiu in view of its strategic development, with particular focus on two objectives: increasing the number of international partnerships and enhanced mobility. (2020 LBUS Development Strategy, p. 21)

\section{MANAGING CULTURAL DIVERSITY FOR ACADEMIC EXCELLENCE}

As Irina Bokova, Director General of UNESCO, has pointed out "people are more connected than ever, but misunderstandings remain deep between societies and within them. Values, traditions, customs and cultural expressions have moved to the forefront of national politics and international relations." The key to effective intercultural communication is represented by enabling academics with the new skills of plurilingualism and awareness of cultural diversity "as a well spring of creativity, dynamism and sustainability." (Irina Bokova, Director General of UNESCO, speeches (Vienna, Austria, 31 May - 1 June 2012) and (21 May 2013)

The push-pull factors of academic mobility may be summed up as follows: prestige of the host institution; increased competitiveness upon return - both academic and work-related; promotion of cultural values; acquiring intercultural competencies; knowledge and research exchange. According to the UNESCO Convention on the Protection and Promotion of the Diversity of Cultural Expressions, interculturality "refers to the existence and equitable interaction of diverse cultures and the possibility of generating shared cultural expressions through dialogue and mutual respect." (UNESCO Convention on the Protection and Promotion of the Diversity of Cultural Expressions (Paris, 20 Oct.2005)

University differentiation and diversity are key components of current European strategies, particularly reflected in a series of key documents: the Lisbon Agenda, the Bologna Process and, more recently, the Europe 2020 Strategy. Differentiation is a concept mainly entailed by academic ranking and classifications, whereas diversity represents a mission statement of the higher education institution as well as a characteristic of the present status of the international academic context.

Universities nowadays represent poles of excellence in terms of cultural innovation, knowledge creation and transfer to the industry, an interface between home and host country as regards academic mobility (teaching and research mobility); they have a significant role in promoting cultural values and informed intercultural communication, creating academic consortia as well as interacting with the local and business communities. In this respect, the cultural centres affiliated to HEIs represent the best vehicle for raising cultural awareness, informed and coherent understanding of ,otherness”, overcoming the „either/or” perspective.

Lucian Blaga University of Sibiu boasts the first Confucius Institute in Romania, set up in 2007 when Sibiu held the title of European Capital of Culture, and this represents an example of best practice for both effective management and anticipatory leadership.

With its increased focus on internationalization by means of creating new opportunities for international academic partnerships and cross-cultural cooperation, Lucian Blaga University of Sibiu has successfully adapted to global societal changes, acting as a responsive, proactive flexible and information-based organization. (Armstrong, Michael, How to Be an Even Better Manager, (fourth ed.) London: Kogan Page, 1994, p. 21). According to Michael Armstrong, management may be summed up as "deciding what to do and then getting it done through the effective use of resources" (Idem, p.16); it is a process requiring the optimum use of human, financial and material resources. On the other hand, leaders play a key role in setting the right direction for the organization, creating a vision and strategy as well as enabling the accomplishment of university mission, by means of "getting the commitment and cooperation of their team ... encouraging and inspiring individuals to give their best ... to get the group into action to achieve agreed objective ... by willing cooperation, not grudging submission." (Idem, pp. 173-174)

To sum up, the Confucius Institute at Lucian Blaga University of Sibiu has successfully created bridges and strengthened Romanian and Chinese interaction at various levels: academic, cultural, economic. 


\section{REFERENCES}

1. Thomas Keith, "Universities under Attack" London Review of Books, Vol 33, no 24, 15 Dec 2011, pp. 9-10. Web 24 March $2014 \quad$ http://www.lrb.co.uk/v33/n24/keiththomas/universities-under-attack

2. Kim, W. Chan and Mauborgne, Renee (2005) Blue Ocean Strategy. How to Create Uncontested Market Space and Make Competition Irrelevant, Harvard Business Review Press

3. De Bono, Edward (2000) New Thinking for the New Millennium, Penguin Books, London

4. Martha Nussbaum, (2010),,Skills for Life”, TLS, April 30, p. 15

5. Thomas, Keith, „What are universities for?”, TLS May 7/2010; p.13

6. Thomas, Keith, "Universities under Attack" London Review of Books, Vol 33, no 24, 15 Dec 2011, pp. 9-10. Web 24 March 2014 http://www.lrb.co.uk/v33/n24/keiththomas/universities-under-attack
7. Nussbaum, Martha (2012) Not for Profit. Why Democracy Needs the Humanities, Princeton University Press

8. Burdusel, Eva Nicoleta; Oprean, Camelia, "A Holistic Approach to Higher Education: Challenges and Changes for the Sustainable University" in Management of Sustainable Development Journal, vol.3, no.1/2011

9. Sallis, Edward (2002) Total Quality Management in Education, ( $3^{\text {rd }}$ ed) Kogan Page, London

10. 2020 LBUS Development Strategy

11. Androulla Vasilliou, European Commissioner for Education, Culture, Multilingualism and Youth, speeches: 13 Sept 2013; 11 March 2014

12. Adair, John (1991) Not Bosses but Leaders, Kogan Page Limited, London

13. Irina Bokova, Director General of UNESCO, speeches (Vienna, Austria, 31 May - 1 June 2012) and (21 May 2013)

14. UNESCO Convention on the Protection and Promotion of the Diversity of Cultural Expressions (Paris, 20 Oct.2005)

15. Armstrong, Michael (1994) How to Be an Even Better Manager, $\left(4^{\text {th }}\right.$ ed.) Kogan Page, London 